\title{
Quantification of burnt areas as a fundamental parameter for the estimation of spatial and temporal patterns of fire incidence in Canaima National Park (Venezuela)
}

\author{
Roberto Rivera-Lombardi $^{1 *}$, Bibiana Bilbao $^{2}$, Jay Mistry $^{3}$, Andrea Berardi $^{4}$, Jonathan Torres $^{1}$
}

\author{
${ }^{1}$ Universidad Central de Venezuela (UCV), Caracas, Venezuela \\ ${ }^{2}$ Universidad Simón Bolívar (USB), Caracas, Venezuela \\ ${ }^{3}$ Royal Holloway University of London, United Kingdom \\ ${ }^{4}$ The Open University, Buckinghamshire, United Kingdom \\ * e-mail: robertoriveralombardi@gmail.com; bibiana.bilbao@gmail.com; j.mistry@ rhul.ac.uk; \\ andrea.berardi@open.ac.uk; geog.jonathan.torres@gmail.com
}

\begin{abstract}
Canaima National Park (30.000 km2, CNP), inhabited by Pemón indigenous peoples, is considered an important protected area due to its biological and cultural uniqueness. High levels of fire incidence, along forest fire vulnerability represent a threat to both ecosystems and human wellbeing. The purpose of this research was to estimate spatial and temporal patterns of fire occurrence in CNP, through burned areas quantification, during 2014-2015 and 2015-2016 periods, using Landsat-8/OLI satellite data (spatial resolution: $30 \mathrm{~m}$ ). Detection and quantification of burned areas required: 1) visual interpretation of fire scars appearing in 252 images, and 2) QGIS (version 2.18.3) application, to estimate total burnt area and vegetation type affected by the fire. Results indicated that the total burnt area was 64200 ha and 106000 ha during the 2014-2015 and 2015-2016 periods, respectively. These figures represent $2.2 \%$ and $3.7 \%$ of total CNP area, while they represent $5.62 \%$ and $9.26 \%$ of Eastern CNP territory, an area of CNP were grassy savannas are dominant. From the first to the second-year fire incidence increased by $64 \%$. This increase relates to the occurrence during 2015-2016 of one of the most severe ("very strong") ENSO episodes recorded nicknamed as Godzilla. During January 2016, at the highest level of ENSO, no rain was recorded in CNP, and 45,000 ha burned, which represents $43 \%$ of all burned area during that year (Oct 2015-Aug 2016). Although savannas were the most affected areas, forests were very affected in 2015-2016, when fire extended towards these ecosystems when the occurrence of dry extreme atmospheric conditions increased forest vulnerability to fire. The methods used during this research allowed us for the first time to determine -with a high level of confidence- the magnitude of fire activity within CNP. This work represents a fundamental advance in the process of identifying vulnerable areas and defining fire management plans in CNP.
\end{abstract}

Keywords: burned area; spatial and temporal fire incidence patterns; remote sensing, ENSO episodes, Canaima National Park. 